\title{
The Role of Thermal Stress on CHF Admissions in a Tropical Climate \\ Balaji Rajathilakam ${ }^{1}$, Jeffrey H Luk $^{2 *}$, Vijay Anand Palaniswamy ${ }^{1}$ and John R Allegra ${ }^{3}$
}

${ }^{1}$ Sundaram Medical Foundation Hospital, Chennai, Southern India

${ }^{2}$ University Hospitals Case Medical Center, Department of Emergency Medicine, Cleveland, OH, USA

${ }^{3}$ Morristown Memorial Hospital Residency in Emergency Medicine, Morristown, NJ, USA

\begin{abstract}
Objectives: A previous study of emergency department visits for Congestive Heart Failure (CHF) to hospitals in New Jersey revealed a marked increase in the colder months. This was attributed in part to increased demands on the heart in response to cold weather. We speculated that the extreme high temperatures in the tropics would place a similar additional burden on the heart. Therefore, we hypothesized an increase in the number of hospital admissions for $\mathrm{CHF}$ during the warmest months in the tropics.
\end{abstract}

Methods:

Design: Retrospective cohort.

Setting: Community hospital in Chennai, Southern India. 2004.

Participants: All patients ages 15 and older admitted to the hospital from January 1, 2001 to December 31,

Protocol: We examined all hospital inpatient discharge diagnoses and selected those for CHF. We analyzed the data by month, testing for statistical significance using Chi Square and Student's t tests with alpha set at 0.05 .

Results: Of the 6,800 total hospital medical admissions, there were 513 admissions for CHF. Of the CHF visits, $46 \%$ were female and the average age was $66 \pm 12$ years. The four coldest months (average temperature $=29^{\circ} \mathrm{C}$ ) had $1.46(95 \% \mathrm{Cl} 1.12-1.79, p=0.015)$ times more visits than the four warmest months (average temperature $=37^{\circ} \mathrm{C}$ ).

Conclusion: Contrary to our hypothesis, we found a statistically significant decrease in CHF visits in the warmer months. We speculate that the additional burden imposed by thermal stress on the heart may be more than offset by the vasodilatory effect of high ambient temperatures.

Keywords: CHF; Temporal patterns; Temperature; Thermal stress

\section{Introduction}

The effect of temperature on the incidence of Congestive Heart Failure (CHF) hospitalizations may provide insight into precipitating factors Allegra et al. [1] showed an increase in Emergency Department (ED) CHF visits during the winter months in New Jersey, USA with 35\% more CHF visits in December than in August. They postulated multiple factors as possible reasons for the increased incidence of $\mathrm{CHF}$ in the winter months, particularly increased catecholamine release in response to cold weather. Other studies also have suggested that there are increased demands upon the heart in cold weather, such as an increase in blood pressure and urinary catecholamines [2] as well as an increase in heart rate and total peripheral resistance and a decrease in cardiac output [3].

Significant cardiovascular changes also occur in high temperature environments. Heat loss in the body occurs through radiation, conduction-convection, and evaporation, which are all dependent on cutaneous blood flow. When the core temperature increases, the dermal vasculature dilates, which decreases systemic vascular resistance, thereby increasing blood flow and heat delivery to the skin [4,5]. Patients with cardiovascular disease are at an increased risk for heat-related illnesses because their hearts are less able to respond to increased demands caused by high temperatures [6]. During periods of heat waves, an increased risk of death in patients with cardiovascular disease has been previously reported $[5,7,8]$.

Increased temperature can raise heart rate, sometimes as much as "double normal" [9]. Ansari and Burch [10] found that the pulse and respiratory rate increased in a hot, humid environment, which resulted in increases in cardiac output and stroke volume to dissipate the additional heat. Kew et al. [11] postulated that the cardiac abnormalities they found from high ambient temperatures could result from decreased coronary blood flow.

Furthermore, high temperatures have been reported to stimulate the sympathetic nervous system into increasing the production of plasma norepinephrine levels $[12,13]$. Patients with CHF have also been shown to have increased norepinephrine levels, which has been associated with higher severity and poorer prognosis $[14,15]$. Therefore, the additional rise in the plasma norepinephrine level caused by high temperatures may place an additional burden on the heart in patients with CHF.

*Corresponding author: Jeffrey $\mathrm{H}$. Luk, University Hospitals Case Medical Center, Department of Emergency Medicine, Cleveland, OH, USA, Tel: 1-732-7545779; E-mail: jhluk@yahoo.com

Received September 30, 2013; Accepted October 10, 2013; Published Octobe 15,2013

Citation: Rajathilakam B, Luk JH, Palaniswamy VA, Allegra JR (2013) The Role of Thermal Stress on CHF Admissions in a Tropical Climate. Trop Med Surg 1: 145 doi:10.4172/2329-9088.1000145

Copyright: @ 2013 Rajathilakam B, et al. This is an open-access article distributed under the terms of the Creative Commons Attribution License, which permits unrestricted use, distribution, and reproduction in any medium, provided the original author and source are credited. 
Examining the effect of high ambient temperatures on CHF could provide insight into precipitating factors for CHF. In accord with previous articles on CHF in the tropics [16,17], we hypothesized that extreme high temperatures would place an additional burden on the heart and would result in a greater number of admissions to the hospital for $\mathrm{CHF}$ in the warmer months in a tropical climate.

\section{Methods}

\section{Study design}

We performed a retrospective analysis of a computerized database of hospitalized patients.

\section{Study setting and population}

The study population consisted of a cohort of all patients age 15 years and older who were hospitalized in a community hospital in Chennai, Southern India during a 4 -year period between January 1, 2001 and December 31, 2004.

\section{Protocol}

We examined all the discharge diagnoses for the entire study population and selected patients with a discharge diagnosis of CHF.

\section{Data analysis}

The gender, age, and date of each CHF admission were entered into a Microsoft Excel ${ }^{\circledR}$ (Redmond, WA, USA) spreadsheet. We then calculated the total number of CHF admissions for each month. This data set was normalized for each month to account for differences in the number of days in the month. The Chi-squared function in Excel ${ }^{\circledR}$ was used to evaluate for significant differences in uniformity by monthof-year. For the CHF hospitalizations, we calculated ratios of the normalized hospitalizations to the average monthly hospitalizations. By examining the monthly average daily maximum temperatures, we arbitrarily chose to compare the ratios of the four months that had a monthly average daily maximum temperature greater than $35^{\circ} \mathrm{C}$ against the ratios of the four months with the lowest temperatures. We used the two tailed Student's $t$-test (SPSS Version 7.5) to evaluate for statistical significance of these ratios. All tests of statistical significance were conducted with $\alpha=0.05$. This was a retrospective study, so no informed consent was required. The institution review board at the study site approved this project.

\section{Results}

There were 6,800 total hospital medical admissions for patients age 15 years and older in the database. Of the total admissions, $513(7.5 \%)$ had a discharge diagnosis of CHF. Of the $513 \mathrm{CHF}$ admissions, $46 \%$ were female and the average age was $66 \pm 12$ years. CHF admissions by month of year were non-uniform by Chi Square $(p=0.04)$. The ratio of monthly CHF admissions to average monthly admissions for CHF and the average monthly daily maximum temperatures versus month are shown in Figure 1. This graph shows more admissions in the cooler months. The four coldest months from November to February (average daily maximum temperature $=29^{\circ} \mathrm{C}$ ) had 1.46 times (95\% CI $1.12-1.79$, $p=0.015)$ more visits than the four warmest months from April to July (average daily maximum temperature $=37^{\circ} \mathrm{C}$ ).

\section{Discussion}

Contrary to our hypothesis, our study showed fewer CHF admissions during the warmer months compared to the cooler months in the tropical climate of southern India.
Our results are not in accord with another CHF epidemiological study done in a tropical country [16]. That study done in Nigeria showed decreased visits during the cooler months of the year. There may be two reasons for the difference in findings. First, the maximum temperature in the Nigerian study was $35^{\circ} \mathrm{C}$ or less whereas in our study the average daily maximum temperature in the warmer months was $37^{\circ} \mathrm{C}$. Secondly, peripartum CHF contributed to nearly $50 \%$ of the cases during some of the hottest months in the Nigerian study whereas in our study women under the age of 50 accounted for only $4.3 \%$ of the total admissions for CHF. In addition, the differences we found cannot be explained by differences in the age or gender for the two periods, as the average age and gender were similar for the coldest (67 \pm 11 years and $48 \%$ female) and warmest months (65 \pm 13 years and $43 \%$ female).

We postulate that the additional stress placed on the heart by high temperatures may be outweighed by the beneficial effects of peripheral vasodilatation caused by high ambient temperatures. Previous studies have looked at the peripheral vasodilatory effects of high temperatures. Rowell et al. examined the redistribution of blood flow to the periphery during sustained high skin temperatures $[18,19]$. Tei et al. [13] studied the cardiovascular hemodynamic effects of warming on patients with CHF. They found decreased systemic and pulmonary vascular resistances and improved left and right ventricular function.

Past research has also shown vasodilatation through pharmacological means possesses beneficial effects in CHF. Cohn et al. [20] showed a statistically significant reduction in mortality by two years for CHF patients being treated with hydralazine and isosorbide dinitrate. The CONSENSUS trial [21] and SOLVD trial [22] demonstrated the benefit of enalapril, primarily an after load reducer, in decreasing $\mathrm{CHF}$-associated mortality. Nitrates are primarily venodilators, but also dilate arteries at high doses, and they have been shown to be beneficial in treating acute CHF exacerbations [23-25].

Furthermore, it has been shown that high ambient temperatures, such as that present in a sauna, can improve various cardiovascular diseases, including CHF $[12,13,26]$. Tei et al. [13] not only found improved cardiovascular hemodynamics in chronic CHF patients after a warm-water bath or sauna, but also reported that repeated thermal vasodilatation led to improved quality of life through increased daily activities and improved appetite, sleep quality, and general well-being. Kihara et al. [27] demonstrated that two weeks of sauna therapy improved vascular endothelial function and decreased plasma brain natriuretic peptide concentrations in patients with CHF.

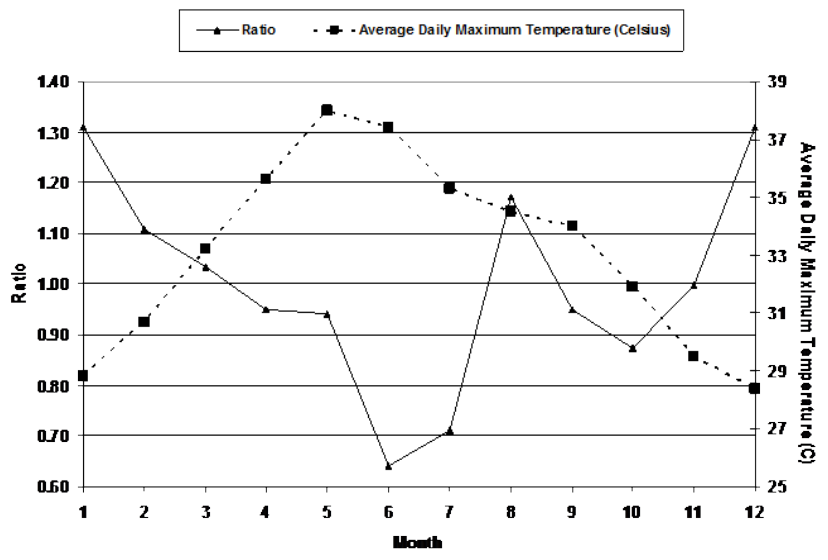

Figure 1: The ratio of the monthly CHF visits to the average monthly visits for $\mathrm{CHF}$ and the average daily maximum temperature Vs month. 
All of these studies support the supposition that the decreased number of CHF admissions that we found during the warmest months in a tropical climate is due to vasodilatation. This reasoning is also consistent with the recent change in opinion regarding the most appropriate treatment of acute decompensated heart failure $[28,29]$.

There were a number of limitations in this study. Our data did not include information on severity of illness. It is also unclear whether there were seasonal differences in the severity of illness. In addition, we did not have information about patient compliance with medications and diet. However, we do not believe these factors would change by season of the year. The data here is not representative of all hospitals in India, particularly those in the rural setting. The differences we found may have been due in part to seasonal changes in the population served by this hospital due to vacations. However, we believe the seasonal changes in the population are small as a survey of 50 patients greater than 50 years old seen in the ED during a cooler month revealed that none of them leave Chennai during the warmest months. Furthermore, our results may not pertain to other locales, such as those in which the climate does not exhibit similar extreme variations in temperature or those where air conditioning is in widespread use. In addition, the applicability of our study results to locales other than Southern India may be limited, as we did not address differences in the aetiology of heart failure that may exist in different areas of the world.

In conclusion, fewer CHF admissions to the hospital occurred during the months of highest temperatures in a tropical climate compared to that during the coolest months. We speculate that peripheral vasodilatation more than offsets the increased cardiac burden imposed by high temperatures.

\section{References}

1. Allegra JR, Cochrane DG, Biglow R (2001) Monthly, weekly, and daily patterns in the incidence of congestive heart failure. Acad Emerg Med 8: 682-685.

2. Sharma BK, Sagar S, Sood GK, Varma S, Kalra OP (1990) Seasonal variations of arterial blood pressure in normotensive and essential hypertensives. Indian Heart J 42: 66-72.

3. Izzo JL Jr, Larrabee PS, Sander E, Lillis LM (1990) Hemodynamics of seasonal adaptation. Am J Hypertens 3: 405-407.

4. Levick JR (2003). An Introduction in Cardiovascular Physiology. (4thedn). Oxford, New York.

5. Arbab-Zadeh A, Crandall CG, Levine BD (2002) Thermoregulation in patients with cardiac disease. J Cardiopulm Rehabil 22: 38-39.

6. Carroll $P(2002)$ The heat is on: protecting your patients from nature's silent killer. Home Healthc Nurse 20: 376-385.

7. Semenza JC, Rubin CH, Falter KH, Selanikio JD, Flanders WD, et al. (1996) Heat-related deaths during the July 1995 heat wave in Chicago. N Engl J Med 335: 84-90.

8. Russo A, Bisanti $L$ (2004) Heat wave effect on frail population in metropolitan Milano, Italy. Epidemiology 15(4): S97-S98.

9. Guyton AC, Hall JE (2000) Textbook of Medical Physiology. (10thedn). W.B. Saunders Company, Philadelphia.

10. Ansari A, Burch GE (1969) Influence of hot environments on the cardiovascular system. A clinical study of 23 cardiac patients at rest. Arch Intern Med 123: $371-378$.
11. Kew MC, Tucker RB, Bersohn I, Seftel HC (1969) The heart in heatstroke. Am Heart J 77: 324-335.

12. Keast ML, Adamo KB (2000) The Finnish sauna bath and its use in patients with cardiovascular disease. J Cardiopulm Rehabil 20: 225-230.

13. Tei C, Horikiri Y, Park JC, Jeong JW, Chang KS, et al. (1995) Acute hemodynamic improvement by thermal vasodilation in congestive heart failure. Circulation 91: 2582-2590.

14. Cohn JN, Levine TB, Olivari MT, Garberg V, Lura D, et al. (1984) Plasma norepinephrine as a guide to prognosis in patients with chronic congestive heart failure. N Engl J Med 311: 819-823.

15. Francis GS, Benedict C, Johnstone DE, Kirlin PC, Nicklas J, et al. (1990) Comparison of neuroendocrine activation in patients with left ventricular dysfunction with and without congestive heart failure. A substudy of the Studies of Left Ventricular Dysfunction (SOLVD). Circulation 82: 1724-1729.

16. Parry EH, Davidson NM, Ladipo GO, Watkins H (1977) Seasonal variation of cardiac failure in northern Nigeria. Lancet 1: 1023-1025.

17. Sanderson JE (1977) Oedema and heart-failure in the tropics. Lancet 2: 11591161.

18. Rowell LB, Brengelmann GL, Blackmon JR, Murray JA (1970) Redistribution of blood flow during sustained high skin temperature in resting man. $\mathrm{J}$ Appl Physiol 28: 415-420.

19. Rowell LB, Brengelmann GL, Detry JM, Wyss C (1971) Venomotor responses to rapid changes in skin temperature in exercising man. J Appl Physiol 30: 64-71.

20. Cohn JN, Archibald DG, Ziesche S, Franciosa JA, Harston WE, et al. (1986) Effect of vasodilator therapy on mortality in chronic congestive heart failure. Results of a Veterans Administration Cooperative Study. N Engl J Med 314: 1547-1552.

21. (1987) Effects of enalapril on mortality in severe congestive heart failure Results of the Cooperative North Scandinavian Enalapril Survival Study (CONSENSUS). The CONSENSUS Trial Study Group. N Engl J Med 316: 1429-1435.

22. (1991) Effect of enalapril on survival in patients with reduced left ventricular ejection fractions and congestive heart failure. The SOLVD Investigators. N Engl J Med 325: 293-302.

23. Cotter G, Metzkor E, Kaluski E, Faigenberg Z, Miller R, et al. (1998) Randomised trial of high-dose isosorbide dinitrate plus low-dose furosemide versus high-dose furosemide plus low-dose isosorbide dinitrate in severe pulmonary oedema. Lancet 351: 389-393.

24. Bussmann WD, Schupp D (1978) Effect of sublingual nitroglycerin in emergency treatment of severe pulmonary edema. Am J Cardiol 41: 931-936.

25. Hoffman JR, Reynolds S (1987) Comparison of nitroglycerin, morphine and furosemide in treatment of presumed pre-hospital pulmonary edema. Chest 92: $586-593$

26. Nguyen Y, Naseer N, Frishman WH (2004) Sauna as a therapeutic option for cardiovascular disease. Cardiol Rev 12: 321-324.

27. Kihara T, Biro S, Imamura M, Yoshifuku S, Takasaki K, et al. (2002) Repeated sauna treatment improves vascular endothelial and cardiac function in patients with chronic heart failure. J Am Coll Cardiol 39: 754-759.

28. Cotter G, Kaluski E, Moshkovitz Y, Milovanov O, Krakover R, et al. (2001) Pulmonary edema: new insight on pathogenesis and treatment. Curr Opin Cardiol 16: 159-163.

29. Sharma M, Teerlink JR (2004) A rational approach for the treatment of acute heart failure: current strategies and future options. Curr Opin Cardiol 19: 254263. 